evidence of the power of the company's technology," says Roger Whiting, senior vice president at Roche.

Underlying Alanex's approach, according the company's director of business development and strategic planning, Ed Baracchini, is its integrated software system-LiBrain-which "thinks" like a medicinal chemist. "When given the task to design libraries with druglike properties, LiBrain, in real time, automatically searches through a toolbox of over 60 known synthetic chemical protocols and a catalog of commercially available reagents, and directs the parallel high-speed organic synthesis of large numbers of templates." The process is-like medicinal chemistry-inherently iterative, with biological activity obtained from screening an initial library immediately fed back into the computational system to enable LiBrain to re-design and synthesize a more focused library.

Meg Malloy, senior biotechnology analyst at Hambrecht and Quist (New York) sees merit in their approach. "Utility [of combinatorial chemistry] in part will be a function of the screening systems in which you evaluate the compounds." Focusing on the biology and being able to quickly relay the information back to the medicinal chemist makes the Alanex system interesting."

Cambridge Combinatorial (CC; Cambridge, UK), one of the newest additions to the combinatorial chemistry scene, is like Alanex in wanting to provide combinatorial chemistry that recognizes the needs of the medicinal chemist. The company was founded only at the end of February, with former Pfizer (Sittingbourne, UK) research leaders Ryszard Kobylecki and Allan Marchington as technical director and chief executive, respectively. $\mathrm{CC}$ aims to provide relatively small but highly characterized and well-organized libraries.

"Several months ago, I was looking at presentations from many combinatorial companies," says Marchington, "and none of them was really providing what pharmaceutical companies wanted. Like Alanex, CC will provide "drug-like structures." Its selling point, Marchington believes, will be the fact that its compounds will be available in microgram amounts produced to good manufacturing practice (GMP) standards. If a client company wants more of a given set of compound, $\mathrm{CC}$ will be able to identify them and generate them to the same standard, he says.

The startup has been funded by a $\$ 3.3$ million seed investment from the Oxford Molecular Group (OM; Oxford, UK), whose chief executive is Allan Marchington's elder brother, Tony. OM will source its own combinatorial chemistry requirements from CC.

Debra Robertson

\title{
Bill mandates patent extension if PTO dallies
}

US biotechnology companies made uncomfortable by the revamped patent legislation that accompanied the GATT (General Agreements on Tariffs and Trade) treaty in 1994 can breathe a sigh of relief if new legislation originating in the House of Representatives is passed by the US Congress. The bill (HR400) was introduced at the beginning of January and would protect companies from delays in processing at the US Patent and Trademark Office (PTO, Washington, DC) by granting extensions to patents as compensation for delays.

"It would give [the biotechnology industry] concrete assurance that it will get a full 17 years of patent term," says David Schmickel, patent and legal counsel for the US Biotechnology Industry Organization (BIO; Washington, DC), who expects the bill to be passed by Congress. The GATT treaty granted patent rights to the inventor 20 years from the filing date, which suited most patent seekers, since the average delay is just 1.5 years. But biotechnology patents-contentious and complex as they often are-can exact long delays from the PTO, up to 10 years or more in certain instances.

The new bill would include some measures to address problems arising from GATT legislation, such as interference delays (when two or more parties claim the same invention-an isolated gene, for example) and delays resulting from appeals to applications initially denied by the PTO. But the bill would take it a step further, requiring the PTO to respond to the initial application within 14 months, and within 4 months for every communication after that. Slower responses would result in an extension to the patent, once issued.

Given that an inventor has 3-6 months to respond to a PTO action, those time limits should guarantee a company at least 2 or 3 office actions on the patent's merits within 3 years, says biotechnology patent attorney Ken Chahine of Madson \& Metcalf (Salt Lake City, UT). That alone makes the new legislation attractive to him. "I have some patents that have gone two years without an action," he says. "This bill (guarantees) you good, solid communication with the patent office, so that you can at least argue a couple of times before you

Jim Kling is an independent science writer working in Bellingham, WA. have to appeal it."

The bill boosts the upper limit on extensions for administrative delays from 5 years under GATT to 10 years, with no upper limit for the time spent in appeals and interference.

The new bill would be an improvement, says Chahine, but he isn't sure that it will shorten the time the PTO takes to consider applications. The compensation for delays "takes some of the pressure off the patent office," he says. And the increased patent term doesn't cover all the costs of delays. "Until a patent is actually issued, you really can't bring an infringement suit against an offender. . hopefully that pressure [will] keep the PTO on its toes," says Chahine. The bill also leaves the definition of "administrative delay" open to interpretation. If the PTO misplaces application materials - not an uncommon happening, according to Chahine-is that considered a delay? "The statute doesn't specifically say," adds Chahine.

HR400, if passed, will preface another bill to increase patent protection for delays in the US Food and Drug Administration (FDA, Rockville, MD) approval process, says Schmickel: "The Senate has made it very clear that as soon as patent term is fixed they'll next look at Hatch/Waxman (the bill that currently governs extensions for FDA approval delays)."

New legislation aims to extend protection beyond the current two to five year extensions allowed by Hatch/Waxman. The time devoured by long-term clinical trials often leaves little protection peroid left, especially if the approval is for a secondary indication or a new indication for a previously patented therapeutic compound. "Without [significant extensions], there is no incentive to bear the cost of all of those FDA trials when you're only looking at a year or two of patent term after you finish," says Schmickel.

"The [difference in price] between something with exclusivity and without may be tenfold, where $90 \%$ of the price is recouping research and development costs," says Schmickel. That is of particular concern to biotechnology companies, so many of whom are developing orphan drugs. The smaller market potential requires more years of exclusivity to recover costs. The current patent legislation is critical, says Eric Christansen, director of public relations at BIO. "Patent term translates into cash life for our companies."

Jim Kling 